\title{
Characteristic Analysis using the Landscape Preference in the Urban Historic Temple
}

\author{
Sung-Ho Kil* \\ Department of Ecological Landscape Architecture Design, Kangwon National University, Chuncheon 24341, South Korea
}

\begin{abstract}
The traditional temple in the urban landscape is a place of historical and cultural heritage with ethnic values within the city. However, when viewed in a landscape perspective, several problems are implied. This is because the temple is restricted within the territories of the temple when there is a great need for space for gatherers and tourists. Thus, a dissimilar landscape planning and management system from the current traditional temple is required. In this study, the landscape of the traditional temple in the city viewed from Bongeunsa temple grounds was set as the study area and the representative viewpoints within the temple grounds were used as a base of describing the landscape's image and the factors of the landscape preference was also derived. These factors were then used as a base to create the landscape preference map for the region of Bongeunsa temple to present a visual representative of the place. The factors showed a significant impact on the landscape of Bongeunsa temple were selected to aesthetics, amiability and complexity. The higher the preference of these factors was, the higher the preference was for the landscape as well. The factors representing the landscape image and the landscape map according to the landscape preference of the temple were created to allow regions that showed both low and high levels in the landscape image and preference within the grounds to be visually classified and regions that needed improvements were also displayed. Furthermore, it also allowed elements to be extracted from it. The results of this study was an attempt in creating the landscape map formed based on the landscape of the temple grounds.
\end{abstract}

Keywords: air ion, air Vitamin, correlation analysis, GVZ

\section{Introduction}

\section{Background and Purpose}

Korea has a long history of over five thousand years and rich cultural assets, and Buddhist cultural assets account for a large share (24\%) of the entire cultural properties (Kim, 1984). This shows that Buddhism has been a spiritual way of life for Korean people, and Buddhist temples, a central space for spiritual activities, have been recognized as a meaningful place where the core philosophy of Buddhism is captured. Temples are a place for Buddhist ceremonies, a place for living for Buddhist monks, and a place for spiritual resting for the public (Park, 2001). In particular, temples in urban areas are not just a place for religious activities, but also, an ecological place that provides people living in urban areas with green spaces as well as opportunities to enjoy the natural landscape and their leisure time, being a landscape of religious, 
spiritual and ecological values. In addition, temples in urban areas are easy to access, and visited by many visitors, and thus it is necessary for temples in urban areas to plan and manage their landscape in a differentiated way in order to secure a large space for visitors inside.

For temples in urban areas not just to function as a religious, historical, cultural and ecological place, but also to play a role as a tourist attraction, it is necessary to manage their sense of place considering landscape images. Negative changes in the landscapes of temples damage the sense of place of the traditional temples as a cultural and religious place, and ultimately result in a loss of the identify of a community (Yi et al., 2010), which increases the importance of landscape management. Managing landscapes means preserving positive landscape elements and restoring negative elements, rather then creating a new landscape (Jung et al., 2008). Earlier studies on temples, however, were conducted mostly from the perspective of art history or religion, and rarely from the perspective of landscape management.

Against this backdrop, this study aimed to select representative viewpoints inside a temple in an urban area, to identify landscape preference factors using landscape adjectives, and to create landscape preference maps based on the results. By doing so, a spatial assessment was conducted on its visual landscapes to suggest landscape areas and factors that need to be improved in a comprehensible way. This study is expected to contribute to developing plans to preserve and manage the landscapes of temples in urban areas, and expanding the methodology for landscape assessment.

\section{Theoretical Background}

\section{Analytical studies on landscape preference elements in urban areas}

Landscape assessment and analysis methods using landscape adjectives for the analysis of the landscapes of urban areas are very useful methods not just to assess the aesthetic value of landscapes, but also to identify the diverse characteristics and values of landscapes (Lim, 2008). Joo and Im (2003) categorized the types of landscape adjectives and made a list of them as an analysis tool for urban landscapes. Song et al. (2007) conducted a questionnaire survey using landscape adjectives to preserve representative urban landscapes, and analyzed their visual structure and landscape preference. Kim (2008) also conducted a questionnaire survey using landscape adjectives to identify the impact of the physical elements of urban landscapes on landscape preference, and analyzed the results statistically.

\section{Studies on the landscapes of temples}

There are some studies that examined problems in the landscapes of traditional temples in modern times and searched for ways to address such problems. Cho (2005) viewed the value of temples from a sense of place, reviewed landscape elements and measures to improve the landscape of the entrance of temples in a harmonious way with the nature and surrounding environment, and suggested measures to improve the overall landscape of temples. Hong (2000) examined the status and problems of the landscapes of modern temples in urban areas, and suggested directions for modern temples as a means to deliver the images and sense of place of traditional temples. Yi et al. (2010) examined the impact of artificial structures (photovoltaic power system) installed at the entrance of traditional temples on their landscapes and suggested the values of traditional temples and measures to preserve their original images and sense of place.

\section{Studies on the sense of place}

Yi (1996) pointed out that studies on the preservation of the environment of traditional temples should be conducted focusing on the importance of temples because they have a positive sense of place including religious functions and cultural and historical values. Lim et al. (2012) analyzed distribution patterns in the place identity of parks to use them as a tool to identify the relationship between their sense of place and other relevant factors. 


\section{Discussion on relevant studies}

Earlier studies on the analysis methods for the preference elements of urban landscapes mostly used landscape adjectives in order to identify the characteristics and meanings of landscapes and to suggest landscape preference. Some studies highlighted the importance of the positive sense of place of traditional temples, or examined factors associated with the sense of place of traditional temples by creating detailed maps. Studies on the landscapes of temples focused on the entrance of temples or analyzed and suggested measures to improve the landscapes of modern temples in urban areas. Therefore, given the fact that most activities are done inside temples, it is necessary to analyze the landscapes of the inside spaces of temples using landscape adjectives, to identify landscape preference factors, and to analyze their spatial characteristics in order to preserve and manage their landscapes in consideration of the sense of place of temples.

\section{Materials and Methods}

\section{Selection of a Study Area}

The purposes of this study are to analyze the landscape preference elements of a traditional temple in urban areas, and to create the landscape preference maps of the temple. To do so, Bongeunsa was selected as a study area in this study. Bongeunsa is a traditional temple located in the center of Seoul (Samsung-dong, Gangnam-gu in Seoul) and it is visited by a large number of Buddhists and tourists (Fig. 1).

Bongeunsa is a traditional Buddhist temple, and the name first appeared in Jikgwanji (Monograph on Officials), the section of Samguksagi (the Chronicles of the Three States) as "Bongeunsaseongjeon (奉恩寺成典)" and "Sichangbongeunsa (始創奉恩寺)” which means that Bongeunsa was first founded in July, in autumn in the $12^{\text {th }}$ year of King Wonseong (Jung, 2008). This shows that Bongeunsa was the weonchal (vow temple) of the royal family of the Silla Kingdom in the capital of Silla. In the $17^{\text {th }}$ year of King Myeongjong (1592) in the Joseon Dynasty, the temple was relocated to the current location in Sudosan Mountain. However, the most part of the temple was destroyed in 1950 during the Korean War, and it was rebuilt as the Jogye Order of Korean Buddhism was established in the 1960s. Since then, the temple has transformed from a traditional temple to an urban temple (Jung, 2008).

As the history of Bongeunsa shows, it is located in the center of Seoul, which is easily accessible using various transportation modes, and City Airport and a large-scale convention center (COEX) are located near the temple. As it is easily accessible for Buddhists and visitors, the characteristics of both modern city and traditional temple are observed at the same time. In this regard, the temple was found to be suitable for this study which aimed to analyze landscape preference elements considering the sense of place of a traditional temple in an urban area. Since the surrounding of the temple has a limited view, and there are many high-rise buildings around the temple, the landscapes seen from inside the temple were analyzed only.

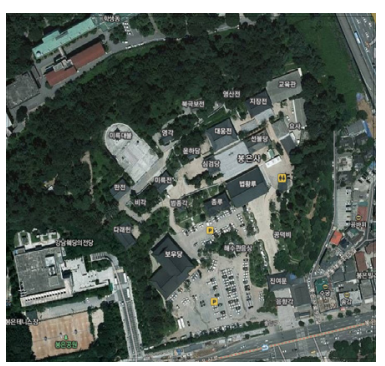

(a) Study site

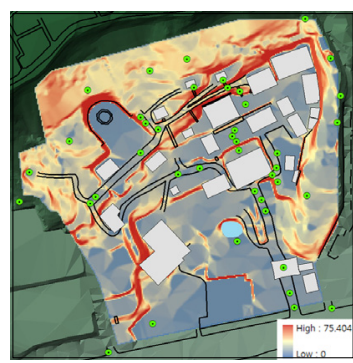

(b) Slope angle

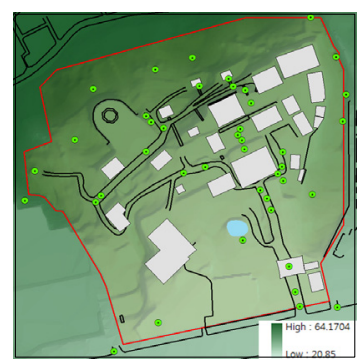

(c) Elevation

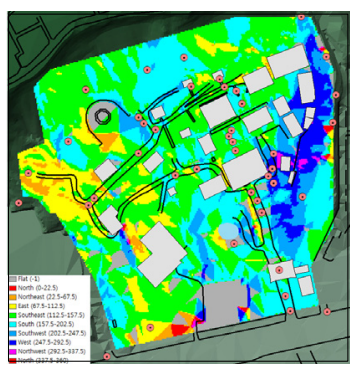

(d) Aspect

Figure 1. Site analysis (Bong-Eun temple pictures by using the Arcgis 9.3). 


\section{Methods}

\section{Selection of viewpoints}

In planning and managing landscapes, it is necessary to select viewpoints based on objective and reasonable standards (Lim, 2008). Song and Son (2011) selected viewpoints within the visibility range of landscapes in consideration of the actual views and the sense of place of viewpoints, and Kim and Song (2010) selected those that have multiple viewing opportunities. This study aimed to analyze the characteristics of landscape preference considering the sense of place of Bongeunsa, as a traditional temple in an urban area that has religious, cultural and ecological functions, and, given the purpose of this study, viewpoints were selected considering the locations and directions of the viewpoints of visitors. To do so, the behavioral patterns of Buddhists and tourists who visited Bongeunsa were observed. Based on the results, areas and directions where visitors paused to bow their head or to take a photo were recognized as major landscape viewpoints in the temple, and 23 viewpoints were selected. Additionally, 19 viewpoints near the boundary of the temple were included to compare them with the selected major viewpoints, and thus a total of 42 viewpoints were selected as shown in Fig. 2.

\section{Photos}

Based on the results of observing the behavioral patterns of visitors to Bongeunsa, major viewpoints and additional

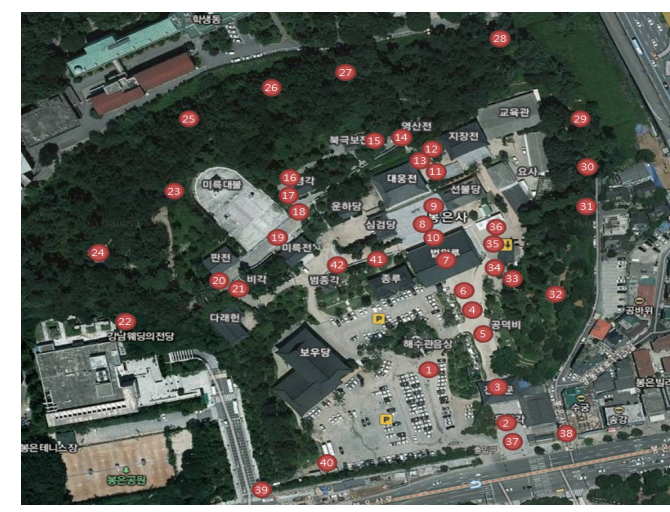

Figure 2. Main viewpoint.

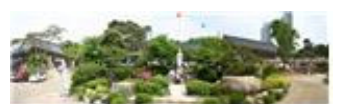

(a) Haesu-gwanum-sang

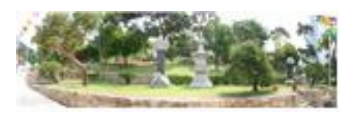

(e) Front of Kongduk-bi

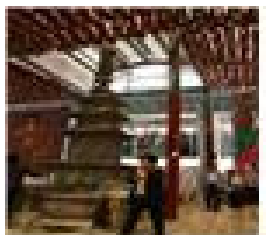

(I) Around a tower

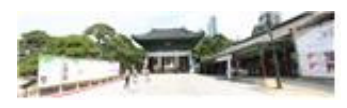

(b) Front of Jinyeou-mun

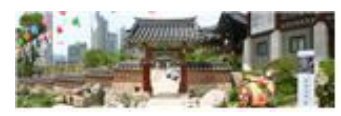

(f) Left Bubwang-ru

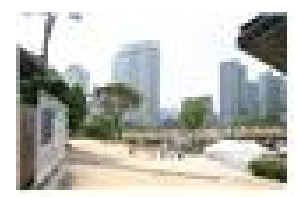

(j) Back side of Daewoong-jeon

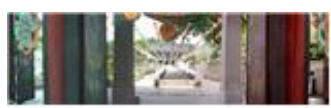

(c) Jinyeou-mun

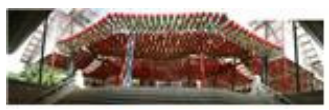

(g) Road going to Daewoong-jeon

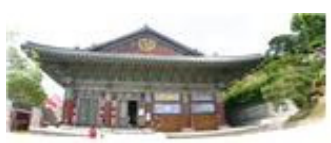

(k) Right Daewoongjeon

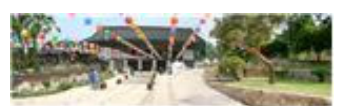

(d) Front of Bubwang-ru

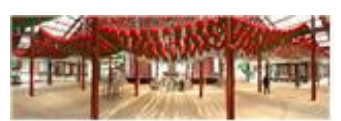

(h) Front of Daewoong-jeon

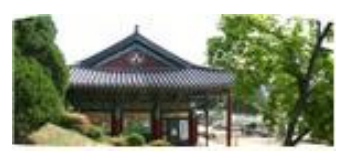

(I) Left side of Jijang-jeon

Figure 3. Photograph of each viewpoint. 


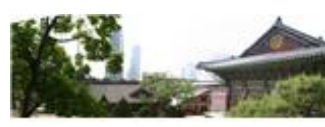

(m) South aspect in left Jijang-jeon

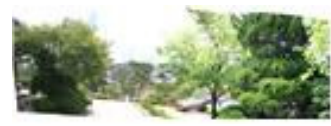

(q) South aspect in left Yong-gak

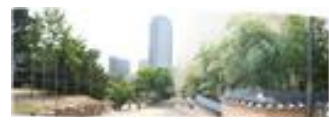

(u) South aspect in left Pan-jeon

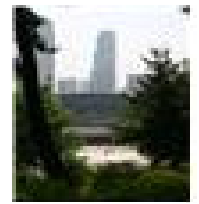

(y) Back mountain of Mireuk-daebu

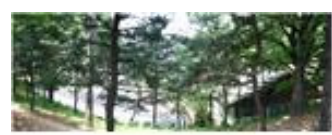

(cc) Between an educational center and a restaurant

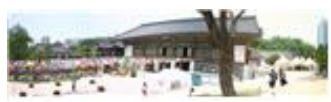

(gg) Sight of Bubwang-ru

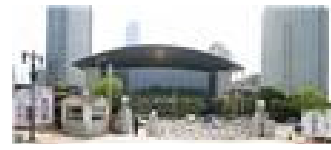

(kk) South aspect of entrance in Bong-eun

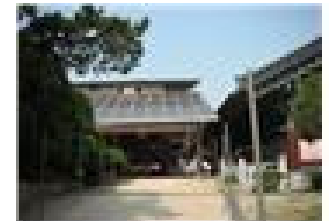

(oo) Left side between Daewoong-jeon and Bubwang-ru

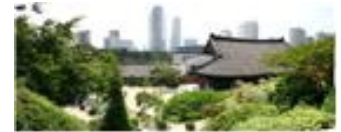

(n) Front of Yongsan-jeon

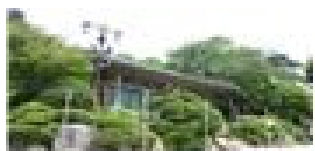

(r) Yong-gak

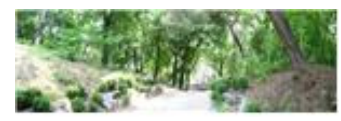

(v) Left Bong-eun cultural center

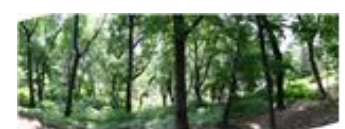

(z) Back Bukgukbojeon (1)

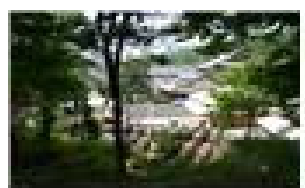

(dd) Jangdokdae of left temple dormitory

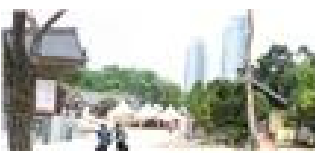

(hh) Sight of apartment building with stores

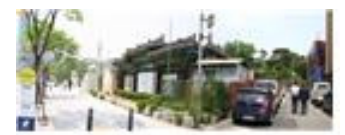

(II) Right-hand corner of Bong-eun

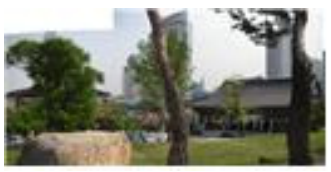

(pp) Rest area around Bumjong-gak

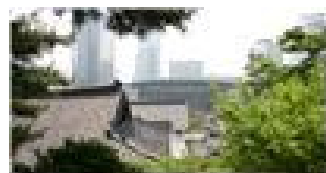

(o) Front of Bukgeokbo-jeon

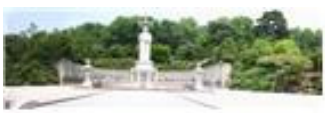

(s) Mireuk-daebul

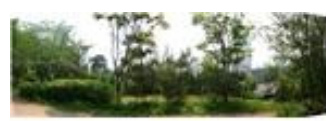

(w) South aspect at the back Mireuk-daebul

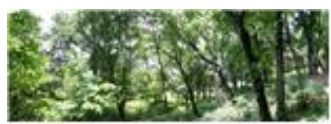

(aa) Back Bukgukbojeon (1)

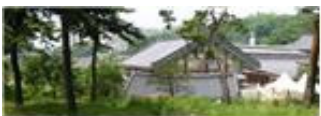

(ee) Sight of Daewoongjeon and Mireuk-daebul

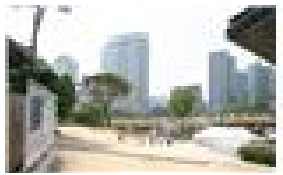

(ii) Sight of Intercontinental hotel

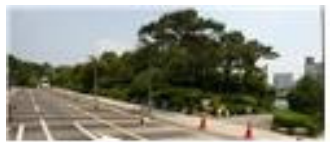

(mm) Left-hand corner of Bong-eun

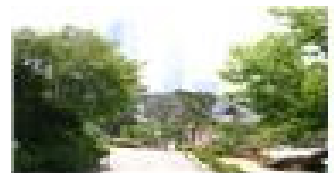

(p) South aspect in Yong-gak

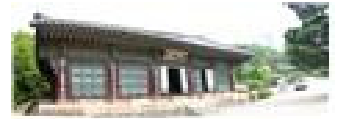

(t) Pan-jeon

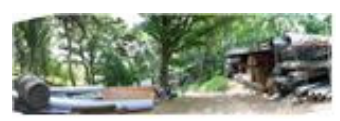

(x) Left top of Bong-eun temple

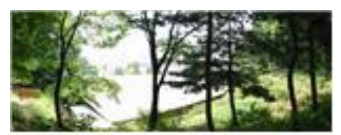

(bb) Back educational center

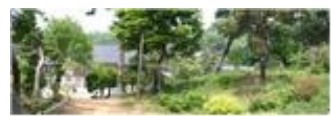

(ff) Sight of Bubwang-ru

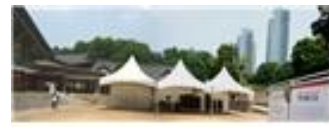

(jj) Right Bubwang-ru

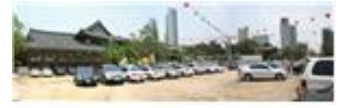

(nn) Left-hand corner of a parking lot

Figure 3. Photograph of each viewpoint (Continued). 
viewpoints near the boundary of Bongeunsa were selected. Photos were taken at the height of $1.6 \mathrm{~m}$ above the ground (eye level) from the selected viewpoints. Photos were taken using a digital camera (EOS-300D, $28 \mathrm{~mm}$, Auto mode), and multiple photos were attached to make a panoramic view in order to secure the landscape seen by tourists and Buddhists from the major viewpoints (Fig. 3).

\section{Survey}

In this study, 10 landscape adjectives were selected among those that have been frequently used in studies on the preservation of historical landscapes (Kim, 2008; Kim, 2006; Park, 2008; Song et al., 2007; Shin, 2006; Yi et al., 2010; Joo and Im, 2003; Kim and Song, 2010) (Table 1).

A photographic survey was conducted among a total of 35 students in master's and doctor's courses who have a relatively profound knowledge of landscapes to increase the validity of results. They were informed of the methods and process of the survey first, and the 42 selected landscape photos of Bongeunsa were shown to them using a beam projector. They were instructed to answer to each question, and one minute was allowed per photo to obtain valid answers. A total of 35 answer sheets were collected, and 5 insufficient answers were exclude. Thus, a total of 30 sheets were used as the final effective sample group.

In this study, 9 independent variables that can affect the landscape preference of each viewpoint within the precinct of Bongeunsa were assessed using an interval scale (from 1 to 7). The dependent variable in this study was landscape preference which indicates the overall feeling of photos including "like the landscape" and "dislike the landscape", and it was assessed using a 7-point interval scale.

\section{Analysis methods}

To verify the reliability of the items measured using landscape adjectives, Cronbach's alpha coefficient was used, and an one-way ANOVA was performed to examine differences between viewpoints. Regression analysis was conducted to identify elements that affect preference among the 9 independent variables using landscape preference as an dependent variable. Data were collected and assessed using Microsoft Office Excel 2010, and AVOVA and multiple regression analysis were performed between variables using SPSS 20.0 for windows.

Table 1. Selected landscape adjectives.

\begin{tabular}{l}
\hline \multicolumn{1}{c}{ Adjectives pairs } \\
\hline open - closed (openness) \\
unique - ordinary (uniqueness) \\
familiar - unfamiliar (familiarity) \\
harmonious - disharmonious (harmoniousness) \\
traditional - modern (traditionality) \\
complicated - simple (complexity) \\
stable - unstable (stability) \\
beautiful - ugly (aesthetic value) \\
natural - artificial (naturalness) \\
like - dislike (preference)
\end{tabular}




\section{Methods to create landscape preference maps}

A landscape preference map for each landscape adjective within the precinct of Bongeunsa was created using an interpolation technique. When data collected from on-site surveys are used directly to create thematic maps, such data are collected only from certain areas due to several limitations such as accessibility, time, cost, etc. For this reason, thematic maps are created in a series of interpolation processes first, and a secondary analysis is performed (Park, 2009). Interpolation is a technique of constructing new data points for areas of which data were not collected using known data points (Kim et al., 2010). There are several interpolation techniques such as IDW (inverse distance weighting), Spline, Kriging, etc., and the IDW method was used in this study.

The mean value of the surveyed data of each landscape adjective was included, and interpolation was performed using the IDW (spatial analyst) of ArcGIS 9.3.

\section{Results and Discussion}

\section{Analysis of Landscape Preference of Major Viewpoints}

\section{Verification of the reliability of variables}

The reliability of the selected 10 pairs of landscape adjectives was verified, and Cronbach's alpha coefficient was 0.7998. When the alpha coefficient is 0.6 or higher, its reliability is recognized to be high in general (Chae, 2005). Thus, the landscape adjectives used as variables in this study were found to be sufficiently reliable (internal consistency).

\section{Analysis of measured preference mean values}

The mean value of the preference of each viewpoint was calculated. Photo $z$ showed the highest score (5.53 out of 7) in preference and it is a viewpoint located in a forest in the backside of Bukgeukbojeon Hall. The viewpoint showed the highest score (6.06) in naturalness. Photo x showed the lowest score (1.77 out of 7) in preference, it is a viewpoint located in the left corner of Bongeunsa where various construction materials lay around disorderly. The difference in preference between the two photos was 3.76 .

\section{Analysis of correlations between variables}

Correlations between variables and their significance probability $(p<0.05)$ were analyzed. Variables that showed a high preference and correlation include stability, familiarity, aesthetic value, harmoniousness, naturalness, and traditionality, and stability showed a high correlation with preference, familiarity, aesthetic value, harmoniousness, naturalness and traditionality. Familiarity also showed a high correlation with preference, stability, aesthetic value, harmoniousness, and naturalness. Aesthetic value showed a high correlation with preference, stability, familiarity, harmoniousness, naturalness and traditionality, and harmoniousness showed a high correlation with preference, stability, familiarity, aesthetic value, naturalness, and traditionality. Naturalness showed a high correlation with preference, stability, familiarity, aesthetic value and harmoniousness.

\section{Analysis of variables that affect preference}

Based on the results of the photographic survey on each viewpoint, multiple regression analysis was conducted to identify variables that affect the dependent variable (landscape preference) among the 9 selected independent variables. As shown in Table 1, the preference pair of "like-dislike" was set as a dependent variable, and the rest 9 pairs were set as an independent variable. Variables were selected using a stepwise method. The reliability of the regression model was 
assessed. The F-value obtained through distribution analysis was 555.927, and its significance level was lower than 0.05 , which indicates that it is suitable for the regression line model. The Durbin-Watson value was 1.890 , which indicates that there is a low possibility of multicollinearity. In addition, the coefficient of determination was 0.978 , and the corrected coefficient of determination was 0.976 . Its significance level was 0.010 , and thus a prediction equation with a very high explanatory power was obtained. The t-test on the regression coefficient also showed statistically significant results. Based on the results of regression analysis, the following regression equation was obtained.

$$
\mathrm{Y}=-0.015+0.728 \mathrm{X} 1+0.380 \mathrm{X} 2+0.107 \mathrm{X} 3
$$

This equation shows that aesthetic value (X1) was found to have the highest impact on the dependent variable (landscape preference, Y), followed by familiarity (X2), and complexity (X3). The results indicate that landscape preference in temples in urban areas can change depending on the level of aesthetic value, familarity and complexity. The results of regression analysis are as shown in Table 2. Suh and Kim (2013) selected three factors (harmoniousness, openness, historicity) through visual-perceptual analysis, and conducted regression analysis on Gyeongbokgung, the main royal palace of the Joseon Dynasty, and harmoniousness showed the highest impact on landscape preference, followed by openness and historicity. These results do not coincide with those of this study, which is attributable to the fact that the study above conducted factor analysis on 13 pairs of landscape adjectives, and conducted regression analysis on 3 factors (harmoniousness, openness, historicity), but that this study conducted stepwise regression analysis on 10 pairs of landscape adjectives, and extracted factors. In the study of Yeo et al. (2012) using the same method, aesthetic value was found to be the most important landscape preference factor, followed by openness. Lee and Kim (2013) also examined the visual characteristics of historical and cultural resources in Seongbuk-dong, Seoul using a method similar to the two methods above. In the study, aesthetic value was found to be the most important factor, followed by cultural factor, and physical factor. These earlier studies conducted a questionnaire survey on landscape adjectives and factor analysis to pair them, named them, and conducted multiple regression analysis to analyze the visual characteristics of historical and cultural resources. The difference between the results of the earlier studies and those of this study is attributable to their different statistical analysis methods, but it is also attributable to differences in landscape preference that respondents felt. However, the methods used in the earlier studies focused on delivering the implications of landscape adjectives, not on finding the representativeness of each landscape adjective, while this study focused on finding the representativeness of each landscape adjective, and applying them to easily create landscape preference maps.

\section{Analysis of Landscape Preference Maps}

\section{Analysis of landscape preference thematic maps}

A survey was conducted on the 42 viewpoints within the precinct of Bongeunsa using 10 landscape adjectives, and the

Table 2. Multi-regression analysis for landscape preference factors.

\begin{tabular}{|c|c|c|c|c|c|}
\hline \multirow{2}{*}{ Model } & \multicolumn{2}{|c|}{ Unstandardized coefficients } & \multirow{2}{*}{$\frac{\text { Standardized coefficients }}{\text { Beta }}$} & \multirow{2}{*}{$\mathrm{t}$} & \multirow{2}{*}{ Sig. } \\
\hline & B & Standard error & & & \\
\hline (Constant) & -1.015 & 0.251 & - & -4.049 & 0.000 \\
\hline Aesthetic value & 0.728 & 0.037 & 0.765 & 19.442 & 0.000 \\
\hline Familiarity & 0.380 & 0.055 & 0.280 & 6.935 & 0.000 \\
\hline Complexity & 0.107 & 0.039 & 0.069 & 2.717 & 0.010 \\
\hline
\end{tabular}


mean values of the results were used to create landscape preference maps (Figure 4). In order to show the sense of place of the viewpoints, this study created thematic maps on openness, complexity, uniqueness, stability, familarity, aesthetic value, harmoniousness, traditionality and preference that the landscape adjectives represent.

The thematic maps of stability, familiarity, aesthetic value, harmoniousness and naturality, which had a high correlation with preference as shown in Table 2, also showed similar patterns to landscape preference. The two viewpoints in the northern part of the temple are located in a forest, and thus they showed a low score in openness, uniqueness and traditionality, but a high score in stability, familiarity, aesthetic value, naturality and preference, which had a high correlation with the dependent variable (preference). The maps showed such correlations between variables visually. In addition, with such landscape preference maps, which areas show high or low preference levels, and which factors affect the landscape preference of the areas can be easily distinguished.

In terms of traditionality, the viewpoint that showed the highest score was that of Daeungjeon Hall, followed by Haesoogwaneumsang, Beopwangru, Yeongsanjeon Hall, Mireukdaebul, and Jinyeomun. They are traditional structures in the temple. The viewpoint that showed the highest score in landscape preference was the forest in the backside of Bukgeukbojeon Hall, which showed a high score in naturality. Viewpoints where temple buildings are seen through trees and where temple buildings and modern buildings are harmonized showed a high score in preference.

Meanwhile, viewpoints near the boundary of the temple showed a low score in traditionality, and viewpoints where the entrance of the temple, banners on the right side of Beopwangru, and steel frames installed to set up tents and lanterns

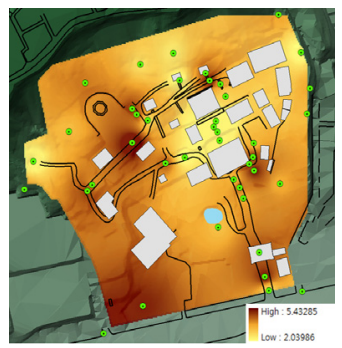

(a) Openness

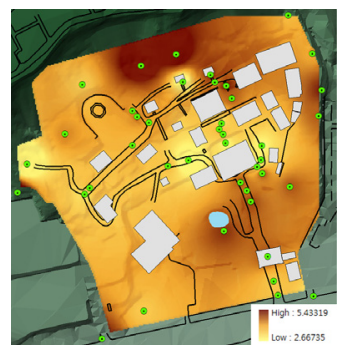

(e) Familiarity

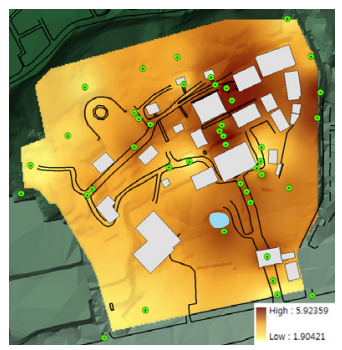

(I) Traditionality

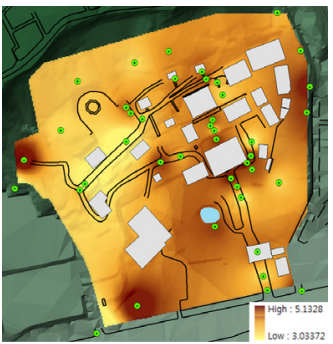

(b) Complexity

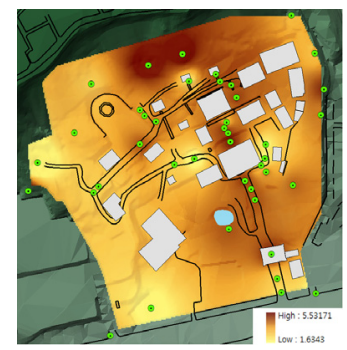

(f) Aesthetic value

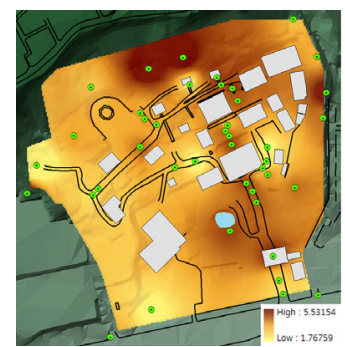

(j) Preference

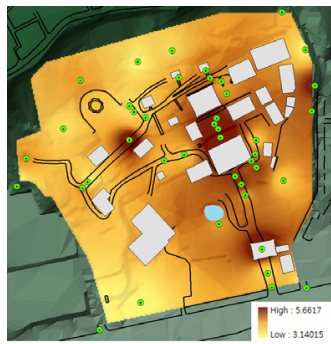

(c) Uniqueness

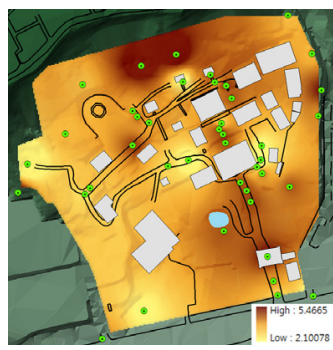

(g) Harmoniousness

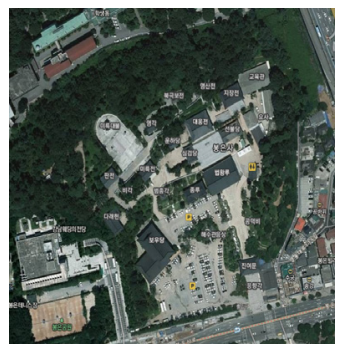

(k) Aerial view of Bong-Eun

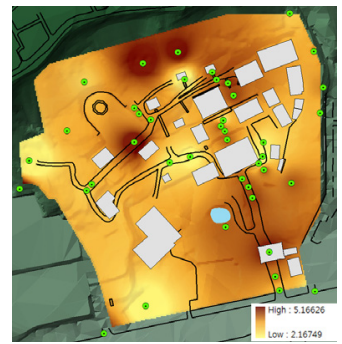

(d) Stability

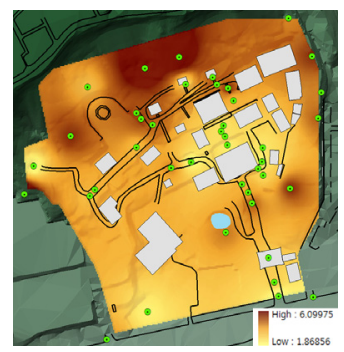

(h) Naturalness

Figure 4. Landscape-preference-map for each factor in Bong-Eun temple. 
showed a low score in preference, requiring improvement. Viewpoints where construction materials were piled up, where temporary buildings and tents were built, where advertising banners, information boards, and steel frames were installed, and where parking lots are seen showed a low score in landscape preference. Suh and Kim (2013) also found that visual preference was higher in viewpoints where modern landscapes did not exist, than those where modern landscapes existed. These results indicate that it is necessary to develop measures to replace modern elements such as banners and tents, and to improve traditionality and naturality, and that tents, temporary buildings and banners that were installed to increase convenience for visitors destroy the landscapes of the temple.

It is recommended to minimize artificial facilities for better landscapes, utilize leaflets instead of information boards, and to adopt materials and designs that can be blended well with surroundings if it is necessary to install artificial facilities. In addition, since viewpoints that showed a high score in traditionality did not always show a high score in landscape preference, it would be better to increase naturality, in the case of temples in urban areas, that is harmonized with modern atmospheres, instead of highlighting traditionality only. Landscape preference maps can be utilized as a basic tool in developing plans to preserve and manage the landscapes of target areas. Areas that show a high score in preference need to be preserved, and those that show a low score in preference need to be improved to increase their preference level.

\section{Conclusions}

In this study, the preference factors and preference levels of major viewpoints within the precinct of a traditional temple in an urban area were identified and examined using landscape adjectives that describe landscape images. Based on the results, landscape preference maps were created. The results of this study can be summarized as follows.

First, it was found that the landscapes of Bongeunsa need to be improved by increasing their aesthetic value, familiarity and complexity. The results of regression analysis on landscape adjectives indicated that aesthetic value and familiarity had the highest impact on landscape preference. Based on the results, the following equation $(\mathrm{Y}=-0.015+0.728 \mathrm{X} 1+$ $0.380 \mathrm{X} 2+0.107 \mathrm{X} 3)$ was obtained, and aesthetic value (X1) showed the highest impact on the dependent variable (landscape preference, Y), followed by familiarity (X2), and complexity (X3). The significance level of the variables was $p<0.01$, indicating that they were statistically significant.

Second, landscape preference maps were created based on major viewpoints within the precinct of the temple. Elements that affect landscape preference were displayed on the maps of the temple, and with the maps the sense of place of the temple was explained. Based on the results, it was possible to visually distinguish areas that showed a high or low level in preference, and to identify areas and elements that need to be improved. These maps can be utilized as a useful tool in developing plans for and managing landscapes. However, it is difficult to say that the scores of each landscape adjective represent such viewpoints, because the adjective represents the landscape that was seen from each viewpoint, not the viewpoint itself. Nonetheless, the reasons why visual landscape preference maps were created in this study are that the maps lay a foundation for easy understanding of the characteristics of the major viewpoints, and that they provide directions for the management of the major viewpoints.

In this study, an interpolation technique was used to visualize landscape preference, and the technique is widely used to construct unknown data points for areas of which data cannot be directly measured in fields such as air pollution and topography. This starts from the assumption that data values that exist in a spatial dimension diffuse or move in a certain direction. However, in this study, landscape preference scores that were observed only from one perspective were used to create landscape preference maps. Other variables such as the use of surrounding lands, altitude difference, facilities, 
direction, materials, texture, color, etc. can have difference effects on landscape maps. To address the limitation, it is necessary to conduct follow-up studies on other factors that can affect landscape preference, such as views, texture and color, and to analyze the landscape preference of each viewpoint through overlay analysis on various factors. It is also necessary to improve landscape preference maps by scoring the status of major viewpoints at a certain time.

In this study, landscape preference maps were created as an attempt to explain the sense of place of a temple by visualizing landscape adjectives. By developing improved guidelines for the creation of landscape preference maps, landscapes can be assessed from a spatial perspective based on the current visual characteristics of the landscapes. Once the application of such landscape preference maps is expanded through mobile and social network service (SNS), they can be used widely in the future.

\section{References}

Chae, S.I. 2005. The method of social science research. Seoul, Korea: BNM books.

Cho, J.S. 2005. A study on arrangement type of commercial district and design elements in approach lane of traditional temples. J. Archit. Insti. Korea Plan. Des. 21(9):67-76.

Hong, K.P. 2000. The desirable landscape of modern temple located in Seoul city. Stud. Buddh. Landsc. Archit. 8:47-71.

Joo, S.H. and S.B. Im. 2003. A study on the landscape adjectives for urban landscape analysis. J. Kor. Insti. Landsc. Archit. 31(1):1-10.

Jung, J.H. 2008. Landscape architecture in Bong-Eun traditional temple. J. Assoc. Korean Buddh. Art Hist. 10:161-191.

Jung, Y.G., T.D. Jo. and J.S. Jeong. 2008. The influence of visual character in types of urban streetscape on preference: In case of the Kangnung-si Joongang-ro. J. Environ. Sci. 17(3):315-323.

Kim, D.C. and M.J. Song. 2010. An analysis of the visual characteristics and preference factors of traditional landscape of rivers in Kangnam region of China: With a case of river in Zhouzhuang, Jiangsu Province of China. J. Korean Inst. Tradit. Landsc. Archit. 28(3):122-130.

Kim, H.Y. 1984. Study on the landscape structure of the Korean buddhist temples and monasteries from the viewpoint of symbolism. MS Thesis, Seoul National University, Seoul, Korea.

Kim, J.H., J.H. Choi. and C.S. Kim. 2010. Comparative evaluation of interpolation accuracy for CO2 emission using GIS. J. Environ. Impact Assess. 19(6):647-656.

Kim, J.P. 2006. A study on the landscape improvement plan of the preserved area of Busosan cultural properties on Buyeo. MS Thesis, Kongju National University, Kongju, Korea.

Kim, Y.J. 2009. A study on the relationship of physical component part and landscape preference of urban landscape : Focus on the Han River. MS thesis, Hongik University, Seoul, Korea.

Lee, W.H. and J.U. Kim. 2013. Research on the visual historical \& cultural resources of Seongbuk-dong. J. Korean Inst. Tradit. Landsc. Archit. 31(2):118-127.

Lim, S.B. 2008. Environmental psychology and human behavior. Seoul, Korea: Bomundang.

Lim, S.B., Y. Kwon, J. Byeon, and H, Choi. 2012. A distribution pattern of the place identity in Daehak-ro. J. Urban Des. Inst. Korea 13(2):105-118.

Park, N.W. 2009. Comparison of univariate kriging algorithms for GIS-based thematic mapping with ground survey data. Korean J. Remote Sens. 25(4):321-338.

Park, S.H. 2008. A Study of landscape image analysis about cultural space in civic center, Seoul. Ph.D Diss., Sangmyung University, Seoul, Korea.

Park, S.Y. 2001. Landscape design for Bong-Eun traditional temple : focus on improvement of the traditional temple problem of the downtown area. MS Thesis, Seoul National University, Seoul, Korea. 
Shin, J.H. 2006. A study on psychological preference characteristics of landscape lighting in buildings of cultural properties. MS Thesis, University of Seoul, Seoul, Korea.

Song, B.H., B. Yang, and G.J. Lee, 2007. An analysis on viewpoint and characteristics of preference for urban landscape management - based on the site of view management in woomyeon mountain. Korea Inst. Ecol. Archit. Environ. J. 7(5):107-114.

Song, M.J. and I. Son. 2011. The Landscape analysis of the modern 'eight famous views(八景)' : A case study on the 12 cities and counties in the Kyeongsangnam-Do. J. Cult. Hist. Geogr. 23(2):79-99.

Suh, J.H. and S.Y. Kim. 2013. Study on characteristics of the visual perception of historic cultural landscape. J. Korean Insti. Tradit. Landsc. Archit. 31(1):108-117.

Yeo, H.S., J.H. Suh, and S.Y. Kim. 2012. An analysis of the visual preference and landscape image of historic-cultural landscape in the city : Mainly the external view point of Gyeongbok-Gung. J. Digit. Des. Res. 35(5):11-20.

Yi, Y.K. 1996. A Study on the Sense of Place of Traditional Temples. Stud. Buddh. Landsc. Archit. 4:59-67.

Yi, Y.K., J.E. Kim, and S.Y. Lee. 2010. Impact of solar energy facility on the landscape experience of traditional temple Focused on the entrance way of Tongdosa. J. Korean Insti. Tradit. Landsc. Archit. 28(3):114-121. 